\title{
Capturing residents' values for urban green space: Mapping, analysis and guidance for practice.
}

\author{
Christopher D. Ives ${ }^{1,2^{*}}$, Cathy Oke ${ }^{1,3}$, Ailish Hehir ${ }^{4}$, Ascelin Gordon ${ }^{1}$, Yan Wang ${ }^{4}$, Sarah A. \\ Bekessy ${ }^{1}$ \\ ${ }^{1}$ School of Global, Urban and Social Studies, RMIT University, Melbourne Australia. \\ ${ }^{2}$ School of Geography, University of Nottingham, Nottingham, United Kingdom. \\ ${ }^{3}$ Clean Air and Urban Landscapes Research Hub, University of Melbourne, Melbourne \\ Australia. \\ ${ }^{4}$ School of Science, RMIT University, Melbourne Australia. \\ * Corresponding author: chris.ives@nottingham.ac.uk
}

\begin{abstract}
Planning for green space is guided by standards and guidelines but there is currently little understanding of the variety of values people assign to green spaces or their determinants. Land use planners need to know what values are associated with different landscape characteristics and how value elicitation techniques can inform decisions. We designed a Public Participation GIS (PPGIS) study and surveyed residents of four urbanising suburbs in the Lower Hunter region of NSW, Australia. Participants assigned dots on maps to indicate places they associated with a typology of values (specific attributes or functions considered important) and negative qualities related to green spaces. The marker points were digitised and aggregated according to discrete park polygons for statistical analysis. People assigned a variety of values to green spaces (such as aesthetic value or social interaction value), which were related to landscape characteristics. Some variables (e.g. distance to water) were statistically associated with multiple open space values. Distance from place of residence however did not strongly influence value assignment after landscape configuration was accounted for. Value compatibility analysis revealed that some values co-occurred in park polygons more than others (e.g. nature value and health/therapeutic value). Results highlight the potential for PPGIS techniques to inform green space planning through the spatial representation of complex human-nature relationships. However, a number of potential pitfalls and challenges should be addressed. These include the non-random spatial arrangement of landscape features that can skew interpretation of results and the need to communicate clearly about theory that underpins results.
\end{abstract}


2 Green spaces in urban environments are vital green infrastructure for a raft of environmental,

3 social and economic benefits (Hunter \& Luck, 2015; Jorgensen \& Gobster, 2010; Swanwick,

4 Dunnett, \& Woolley, 2003). In the past few years, scholars have sought to understand the

5 specific characteristics of green spaces that promote visitation (Grahn, Stigsdotter, \& Berggren-

6 Bärring, 2005), health benefits (McCormack, Rock, Toohey, \& Hignell, 2010) and mental

7 restoration (Nordh, Hartig, Hagerhall, \& Fry, 2009). Recent reviews of the literature have shown

8 that green spaces are indeed important for human health and well-being and environmental

9 sustainability, although the specific mechanisms or pathways for these benefits are often

10 complex (Kabisch, Qureshi, \& Haase, 2015; Konijnendijk, Annerstedt, Nielsen, \&

11 Maruthaveeran, 2013). Social benefits of green spaces in particular have been shown to be

12 influenced by a complex set of factors such as access, maintenance, amenities and perceptions of

13 aesthetic attractiveness and safety (Konijnendijk et al., 2013; McCormack et al., 2010).

15 In contrast to the study of the health and environmental benefits of green space, social values and 16 attitudes towards green spaces and the cultural services they offer have received less attention

17 (Hitchings, 2013). In their review of empirical research on urban ecosystem services, Luederitz

18 et al. (2015) found that cultural services were the least represented group. The values people

19 assign to landscapes can be understood as an expression of these cultural services (Plieninger,

20 Dijks, Oteros-Rozas, \& Bieling, 2013). On a theoretical level, these values exist in the "relational

21 realm", where value "emerges from the interaction between a subject and an object" (Brown,

22 1984). Assessing the values people assign to natural areas is a critical component in sustainable

23 landscape management (Kenter et al., 2015; Plieninger et al., 2015), yet the importance of places 
24 to urban residents will not necessarily be evident from their use patterns alone (Ives \& Kendal,

25 2014; Swanwick, 2009). Indeed, Tyrväinen et al. (2007) in their study of green space values in

26 Helsinki found open spaces that were identified by local residents to be their favourite were not

27 the most frequently used green spaces.

29 Applying assessments of green space values and benefits to planning and management has been

30 identified as an area in need of further research (Luederitz et al., 2015; Tratalos, Haines-Young,

31 Potschin, Fish, \& Church, 2015). Historically, a variety of approaches have been used to plan

32 and manage green space networks (Maruani \& Amit-Cohen, 2007), yet there is a need for greater

33 knowledge of how specific landscape variables influence green space values and how these

34 insights can be applied to planning practice. A challenge of urban landscape planning is

35 reconciling knowledge on how landscapes function (i.e. what $i s$ ) with normative assertions about

36 desired future states and actions towards them (i.e. what ought to be) (Campbell, 2012).

37 Lindholst et al. (2015) identify three scales at which reconciliation between research and

38 planning practice can take place: (i) the conceptual level, where scholarly ideas influence

39 planning frameworks and paradigms, (ii) the policy level, where knowledge can inform planning

40 policies, and (iii) the applied level, where insights on human interactions with ecosystems can

41 provide guidelines and practical advice on planning and management actions. When relating

42 evidence on landscape values to practice, it is therefore important to consider the level at which

43 this integration should occur.

45 If intangible values for green spaces are to be understood and integrated into planning practice,

46 there is a need for methods to capture these values in ways that can be readily applied. Public 
47 Participation Geographic Information System (PPGIS) methods are growing in popularity in

48 applied landscape research because of their ability to engage stakeholders and capture spatially-

49 explicit information on intangible landscape values that can be integrated with existing planning

50 approaches (Brown, 2012; Van Herzele \& van Woerkum, 2011). PPGIS is a field of geographic

51 information science that focuses on the use of geospatial technologies by the public (such as

52 mapping) to participate in public processes (Tulloch, 2008). Mapping activities have been

53 commonplace in community planning for some time, such as the use of maps as stimuli for

54 group dialogue or allowing community members to draw significant landscape features on maps

55 themselves in a deliberative setting (Wates, 2014). While these methods promote deep

56 engagement with the planning process and elicit nuanced local knowledge of an area, the PPGIS

57 method explored in this study is oriented towards greater quantification of this knowledge and

58 broader community representation. Such GIS-based approaches are able to spatially represent

59 community landscape perceptions within a form of data commonly used in decision-making.

60 Kabisch et al. (2015) therefore called for greater use of these techniques in urban environment

61 research because of their ability to connect research with practice.

63 However, while the number of scientific studies using PPGIS has increased over time, there

64 remains some resistance to the use of participatory approaches by planning professionals because

65 expert opinion is seen as superior or more reliable than 'crowd-sourced' information (Brown,

66 2015). Future empirical research that uses PPGIS techniques should therefore consider not only

67 scientific or theoretical issues, but also how PPGIS can be applied in landscape practice. 
69 A number of studies have applied PPGIS techniques to urban systems in recent years with some

70 key insights beginning to emerge. First, a diversity of values have been shown to be assigned by

71 residents to green spaces (Brown, 2008; Tyrväinen et al., 2007), lending empirical support to the

72 notion of landscape value plurality (see Zube, 1987) within urban landscapes. Yet not all mapped

73 values for green space are of equal significance. For example, Kyttä et al. (2013) found the most

74 positive values were associated with attractiveness, ease of walking/cycling and presence of

75 nature, while Tyrväinen et al. (2007) found 'opportunities for activity' and 'beautiful landscape' to

76 be the most frequently assigned social values in green spaces. Second, geographic factors

77 influence the strength and diversity of mapped values. This led Brown (Brown, 2008) to develop

78 a 'theory of urban park geography' using data from a public survey where residents of

79 Anchorage, Alaska identified places on a map of their local area that they valued. Brown (2008)

80 found strong support for the theory that the diversity of park values is positively related to green

81 space size (area), and weak support for a negative relationship between value diversity and the

82 distance of a green space from concentrated human habitation. Similar results were found by

83 Brown et al. (2014) who found that larger green spaces contained more mapped benefits and

84 activities from an online survey in Adelaide, Australia. The influence of geographic proximity as

85 a variable lends support to the theory of spatial discounting of place values (Norton \& Hannon,

86 1997). Finally, other PPGIS studies have shown that specific biophysical and management

87 characteristics of green spaces influence assignment of values. For example, green space

88 classification has been related to the values assigned to the spaces and the activities undertaken

89 within them (Brown et al., 2014; Brown, 2008), and green spaces located in close proximity to a

90 shoreline being found to also be assigned more positive values (Balram \& Dragićević, 2005; 
91 Kyttä et al., 2013). Given PPGIS remains a relatively new technique for assessing relationships

92 between people and green spaces, there is a need for further empirical research on these issues.

94 There are some key outstanding research gaps in the application of PPGIS information on urban 95 green spaces to urban planning. Relevant questions include (i) how applicable are the findings

96 from the few existing PPGIS studies on social values for green space to other regions? (ii) how

97 can statistical techniques be refined to better accommodate the type of data collected in PPGIS

98 studies and what might these tell us about the nature of relationships between mapped values and

99 biophysical green space characteristics? and (iii) what challenges might need to be overcome in

100 order to better apply spatially-mapped social values for green spaces to landscape planning

101 practice? This article addresses these gaps by pursuing the following objectives: (1) assess the 102 spatial representation of positive and negative social values for green space in an urbanising 103 region, (2) analyse their statistical relationships to key environmental values and one another, 104 and (3) consider how PPGIS techniques and these results might be applied to green space 105 planning. We pursue these objectives through undertaking a PPGIS survey of residents' values

106 for green spaces (defined here as open spaces with grass or other vegetation but excluding 107 private gardens and street trees) in an urbanising region of eastern Australia.

109 2. Methods

1102.1 Study area

111 Four suburbs within two Local Government Areas (LGAs) in the Lower Hunter Valley, New 112 South Wales, Australia were selected for the study. The Lower Hunter Valley was experiencing 113 significant land use change, and at the time of the survey was the subject of an extensive regional 
114 planning process that would consider priorities for economic activities, urban growth and

115 conservation (see Raymond \& Curtis, 2013 for details). The four suburbs selected were

116 Charlestown and Toronto (within the Lake Macquarie LGA), and Nelson Bay and Raymond

117 Terrace (within the Port Stephens LGA) (Fig. 1). These suburbs were chosen because they are

118 areas of current and future urban growth and contain a variety of green spaces. Population

119 statistics for the four suburbs were as follows (suburb initials used for brevity): (i) Population -

120 C 12411, T 5433, NB 5396, RT 12725; (ii) Median age - C 39, T 44, NB 47, RT 35; (iii) Number

121 of private dwellings - C 5326, T 2472 NB 4083, RT 5082; (iv) Median weekly household income

122 (AUD) - C \$1244, T \$816, NB \$930, RT \$1003 (Australian Bureau of Statistics, 2011). The total

123 number of formal green spaces delineated in our study area was 323.

\subsection{Survey administration}

126 Survey instruments were developed to ascertain the values that residents in the Lower Hunter

127 Valley assigned to the green spaces in their local area. Survey packets were mailed to a total of

1281,000 residents from the four suburbs in July 2013. Survey recipients had expressed willingness

129 to participate via initial screening telephone calls from a larger database of residents phone

130 numbers. Recipients were asked to indicate their age to ensure that $>20 \%$ were $18-35$ and $>20 \%$

$131 \quad 35-55$ as a way of minimising the bias towards an older demographic which is typical in survey

132 respondents. 418 surveys were returned from a possible 972 (43\%) (28 of the 1000 survey

133 packets were returned to sender). The percentage of responses differed slightly between suburbs

134 as follows: Raymond Terrace $18.4 \%$; Nelson Bay $28.9 \%$; Charlestown $27.8 \%$; and Toronto

$13524.9 \%$. Of the respondents, $50.6 \%$ were male and $43.3 \%$ were female $(7.1 \%$ did not specify

136 their sex). $93 \%$ of respondents nominated the contact address as their principle place of 
137 residence. The median respondent ages for the four suburbs were as follows (with the census

138 median age given in parentheses): Raymond Terrace 57 (census $=35$ ); Nelson Bay 60.5 (census

139 = 47); Charlestown $62($ census $=39)$; Toronto $61($ census $=44)$. We observed an older

140 respondent profile despite efforts to recruit younger participants (see supplementary material S1),

141 however, the difference may not be as pronounced as it appears since the Australian census data

142 includes those under 18 years old.

144 The survey instrument contained the following components: (i) a paper map of the resident's

145 suburb displaying official municipal green spaces, significant roads and walkways and extant

146 tree cover (scale $=1: 13,500$ ); (ii) an interactive map legend with descriptions of green space

147 values and negative qualities corresponding to numbered marker dots for participants to stick to

148 the map (red, $6 \mathrm{~mm}$ diameter, six per value attribute); and (iii) a series of socio-demographic

149 questions including gender, age, education, occupation, income and housing status. For the

150 interactive mapping component, participants were instructed to stick the marker dots denoting

151 specific values to green spaces on the map. Participants could assign as many or as few marker

152 dots as they wished (up to the maximum of six per value type), and were not restricted to placing

153 dots in formally identified green spaces.

155 The 'values for green spaces' associated with the stickers on the map legend were adapted from 156 existing typologies developed for PPGIS studies in the context of urban green spaces (see

157 Brown, 2008; Tyrväinen et al., 2007). The specific value classes and definitions were further 158 refined to ensure content validity and contextual relevance after interviewing key stakeholders 159 such as government, industry and Non-Governmental Organisation representatives from the 
160 Hunter Valley area, meeting with local government staff, and undertaking focus groups with

161 community members from both municipalities. The final typology of values and negative

162 qualities was as follows:

163

164 - Aesthetic / Scenic (e.g. places that are visually attractive)

165 - Activity / Physical Exercise (e.g. places you value because they provide opportunities for $166 \quad$ physical activity)

167 - Native Plants and Animals (e.g. places you value for the protection of native plants and 168 animals)

169 - Nature (e.g. places to experience the natural world)

170 Cultural Significance (e.g. opportunities to express and appreciate culture or cultural

$171 \quad$ practices such as art, music, history or indigenous traditions)

172 - Health/Therapeutic (e.g. places you value for mental or physical restoration)

173 - Social Interaction (e.g. opportunities for you to interact with other people)

175 The 'negative qualities of green spaces' were:

176 - Unappealing (e.g. neglected, damaged, unaesthetic, ugly)

177 - Scary/Unsafe (e.g. dangerous or threatening)

178 - Noisy (i.e. disturbingly loud or noisy)

179 - Unpleasant (unpleasant or exposed to the elements, i.e. too hot, too windy, no shade or $180 \quad$ shelter etc.) 


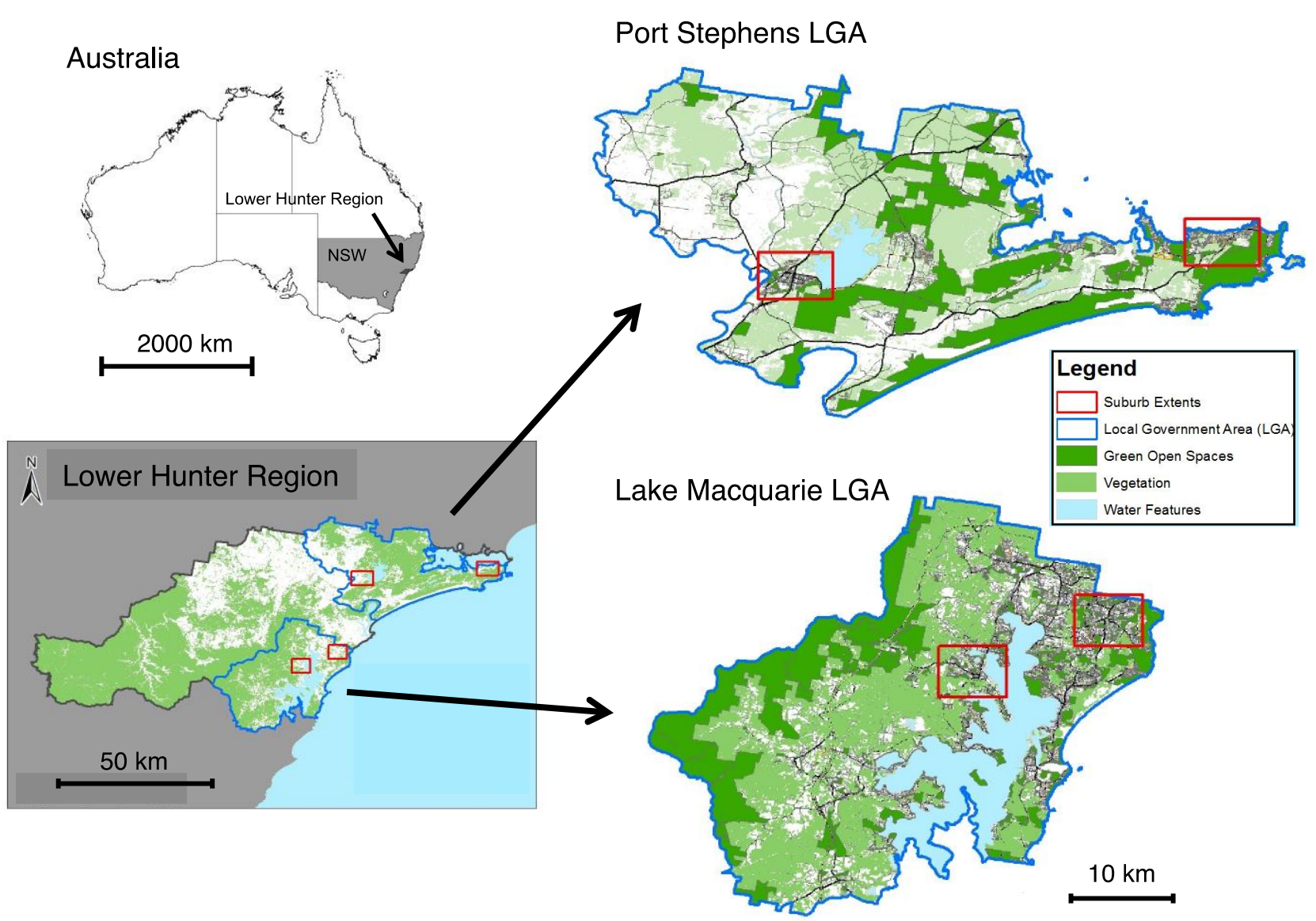

182

183

184

185

186

Figure 1. Maps of the location of the four study suburbs within the two Local Government Areas in NSW, Australia.

To maximise response rates, a series of incentives and reminders were employed according to the Dillman (2007) tailored design method. This included a gift of six packaged postal stamps, an opportunity to win a \$100 AUD shopping voucher, and two reminder postcards and an additional complete survey packet for non respondents distributed at two week intervals where necessary. The survey design and administration procedure was reviewed and approved by [identity hidden for peer review] University's ethics board (project 06/13). 
194 Returned paper maps were scanned at a resolution of 400 dpi and the location of mapped sticker

195 dots digitised to enable spatial analysis in ArcGIS. Spatial data layers were obtained from local

196 councils and the Australian and New South Wales Governments including maps of public open

197 space lands, extant vegetation cover, roads and housing lots and aerial photographs. Google

198 maps, Google street view imagery, and Gregory's Newcastle Street Directory (2012) was used to

199 validate and edit council open space layers. Green space values (as indicated by marker dots)

200 were assigned to green spaces they intersected with, with a spatial tolerance of $80 \mathrm{~m}$ (the width

201 of the marker once assigned to the map). Address locations of survey respondents were manually

202 digitised from volunteered addresses, or in cases where this was information was withheld, the

203 nearest street corner.

205 For each suburb, 'heat' maps of the spatial concentration of assigned marker dots were generated 206 by creating an Inverse Distance Weighted surface to indicate locations of high value for each

207 variable of interest, using Spatial Analyst in ArcGIS. Inverse Distance Weighting determines the

208 value of a cell by interpolating values from nearby cells, with those nearer to the focal cell being 209 given greater weight than those further away. Geometric attributes of green space polygons (e.g.

210 area, width etc.) were calculated using standard Spatial Analyst tools in ArcGIS. The 'near' tool

211 was used to calculate the distance of green spaces from water bodies (sea, lakes, rivers and

212 creeks) and resident's home addresses according to the closest point of approach between these

213 features. Finally, the management categories that green spaces were classified as were assessed.

214 Because the Local Environment Plans of the two LGAs contained different green space

215 management classes, consistency between the LGAs was maintained by assigning green space 
216 polygons to one of three management categories based upon the original plans (see Table 1 for

217 details of this reclassification).

219 Table 1. Management categories assigned to green spaces in the two LGAs studied.

\begin{tabular}{ll}
\hline \multicolumn{2}{c}{ Lake Macquarie Local Government Area } \\
Original Council Classes & $\begin{array}{l}\text { Classification for } \\
\text { Analysis }\end{array}$ \\
\hline General Community & General \\
Natural Areas & Natural \\
Public Parks & General \\
Sportsfield & Sportsfield \\
\hline \multicolumn{1}{c}{ Port Stephens Local Government Area } \\
Original Council Classes & Classification for \\
& Analysis \\
\hline Cultural Significance & General \\
Foreshore & General \\
General Community & General \\
Natural Area & Natural \\
Sportsfield & Sportsfield \\
Urban Park & General \\
\hline
\end{tabular}

\subsection{Statistical analysis}

222 A range of statistical techniques were used to explain why green spaces varied in the number and 223 type of value marker dots. Relationships between green space characteristics and mapped value

224 markers were explored by treating the abundance of value markers within individual green space 225 polygons as the response variable, and the green space characteristics as explanatory variables.

226 The data has excessive zeros, with 100 green spaces (31\%) containing no markers. Green spaces

227 that did not receive markers were on average smaller (mean $=5.26$ ha, s.d. $=10.06$ ha) compared

228 to those without markers $($ mean $=0.62 \mathrm{ha}, \mathrm{s.d} .=1.48 \mathrm{ha})$, and had a smaller perimeter to area

229 ratio (without markers: mean $=11.68$, s.d. $=9.93$; with markers: mean $=29.98$, s.d. $=24.75$ ),

230 suggesting that smaller green spaces were less salient to respondents. The observed variance to

231 mean ratios in the number of markers also demonstrated a clear over-dispersion, ranging from 
23210.57 to 43.25 across all types of positive value makers for green spaces. A hurdle model was

233 deemed appropriate to deal with both these issues. Hurdle models analyse the zero and positive

234 counts separately (Zeileis, Kleiber, \& Jackman, 2008) by using a binomial process to model the

235 likelihood that an observation will have a count of zero and a zero truncated distribution to

236 model the positive counts. We chose a zero truncated negative binomial regression model to

237 handle the over-dispersion. The analyses were conducted using the "pscl" package (Jackman,

238 2015; Zeileis et al., 2008) in R (R Development Core Team, 2015).

240 Environmental characteristics of green spaces were used as either continuous or categorical

241 independent variables in our negative binomial regression model to predict value marker dot

242 abundances. Multicollinearity was reduced by selecting environmental predictor variables to

243 include in the model using a stepwise variance inflation factor (VIF) selection process. This

244 operates in four iterative stages: (1) calculation of a VIF for each variable using the full set of

245 explanatory variables; (2) removal of the variable with the highest VIF value and recalculation

246 all VIF values with the new set of variables; (3) removal of the variable with the next highest

247 VIF value; and (4) replication of the process until all VIF values are below the threshold (5 was

248 selected as a reasonable trade-off between explained variance and model parsimony) (Beckmw,

249 2013). The set of variables selected for further modelling were: percentage of vegetation cover,

250 distance from a significant water body, area, width, perimeter:area ratio, length:width ratio, and

251 the presence/absence of a walking path.

253 Quadratic terms of continuous predictor variables were also included to test for non-linear 254 relationships. Suburb was included and retained as a predictive factor in all the models to 
255 systematically account for any differences between the four study areas. The best models of

256 different green space values were determined through the following process: (1) a negative

257 binomial model was calculated using all predictors, (2) the variable with the highest $P$-value was

258 removed and the model recalculated, (3) the two models were compared using the "vuong"

259 function within the "pscl” R package, with the model with the lower AICc index retained, (4)

260 variables were sequentially dropped using this process until no further improvement in AICc was

261 found. We present only the model results for the positive counts because we are interested in

262 identifying the factors that influence the strength and type of values of green spaces that receive

263 marker dots, not the factors that determine whether or not green spaces receive marker dots at all.

264 Results of the final model were displayed by plotting predictor variable effects to allow visual

265 comparison of model differences. The influence of the green space management classification by

266 local councils (general, natural, sportsfield) on green space values was analysed in separate

267 models because it was not a physically observable variable associated with a green space.

268 Results of models with green space management classification were also displayed graphically,

269 with predicted means of value reported.

271 To analyse the effect of distance from home residence on the assignment of value dots, it was

272 necessary to account for the configuration of green spaces in each suburb relative to the locations

273 of the respondents. For example, if most green spaces occurred close to respondents' home

274 addresses, the distance to green spaces for each respondent would tend to be small, potentially

275 indicating a strong effect of green space distance. But this may be spurious as even if their true

276 preference had no relationship to distance (or indeed their selection of value dots was completely

277 random), respondents would likely select more green spaces close by if these were the majority 
278 of green spaces to choose from. To this end, a null model of green space values was generated

279 for each suburb by randomly assigning 6 'dots' per respondent to green spaces in their suburb.

280 The distribution of the distances between these dots and their home addresses was then

281 calculated. The resulting output represented a distribution of green space distances that resulted

282 solely from the spatial locations of the respondents relative to the green spaces rather than any

283 sort of preference. This could then be compared to the real distribution from the mapped data,

284 with any difference representing the effect respondent's preferences as opposed the effect of the

285 geometry. To understand the difference between these two distributions, they were both plotted

286 as histograms. One histogram was then subtracted from the other resulting in a histogram where

287 the value of each bin represented the difference in the values for each bin of the histogram. The

288 statistical differences between the two distributions were calculated via Chi-squared tests for 289 given probabilities of histogram bins, using simulated p-value (based on 2000 replicates).

291 Finally, the compatibility between different green space values (defined here as the degree of co-

292 occurrence of different value marker dots in individual polygons) was explored through

293 Spearman rank correlations of the abundances of value marker dots, and by factor analysis.

294 Factor analysis of mapped value markers was performed using the 'factanal' package in R (with 295 varimax rotation), with the number of factors determined by viewing eigenvalues on a scree plot.

\section{3. Results}

\section{3.1 Mapping marker dot abundance.}

299 The four suburbs contained a total of 318 distinct green spaces, and 9,186 points were assigned

300 to them by respondents out of a total of 9,691 points assigned to the maps. The most commonly 
301 assigned value marker type was "activity/physical exercise" $(\mathrm{n}=1131)$ while "noisy" received 302 the fewest dots $(\mathrm{n}=131)$ (see Fig. 2)

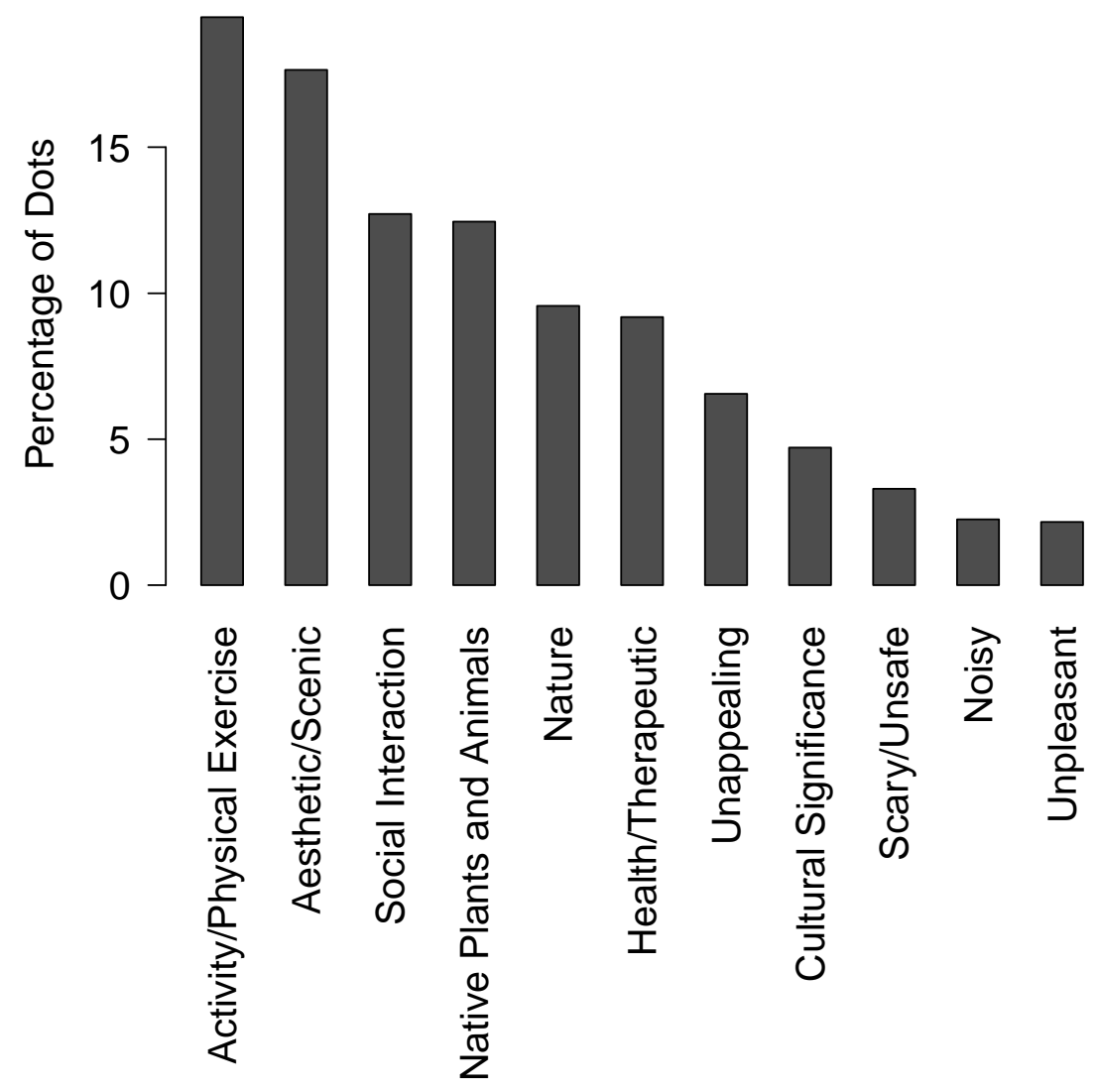

303

304 Figure 2. Proportion of mapped value marker dots across all suburbs.

306 Displaying the spatial location of value markers through the Inverse Distance Weighted surface

307 reveals substantial variability in the location of the bulk of value markers. This technique is

308 particularly useful for communicating results with landscape managers and for displaying

309 visually the differences between various value markers. Examples of this mapping can be seen in

310 Fig. 3, with a complete set of Inverse Distance Weighted maps for the 4 suburbs available as

311 supplementary material S2. 

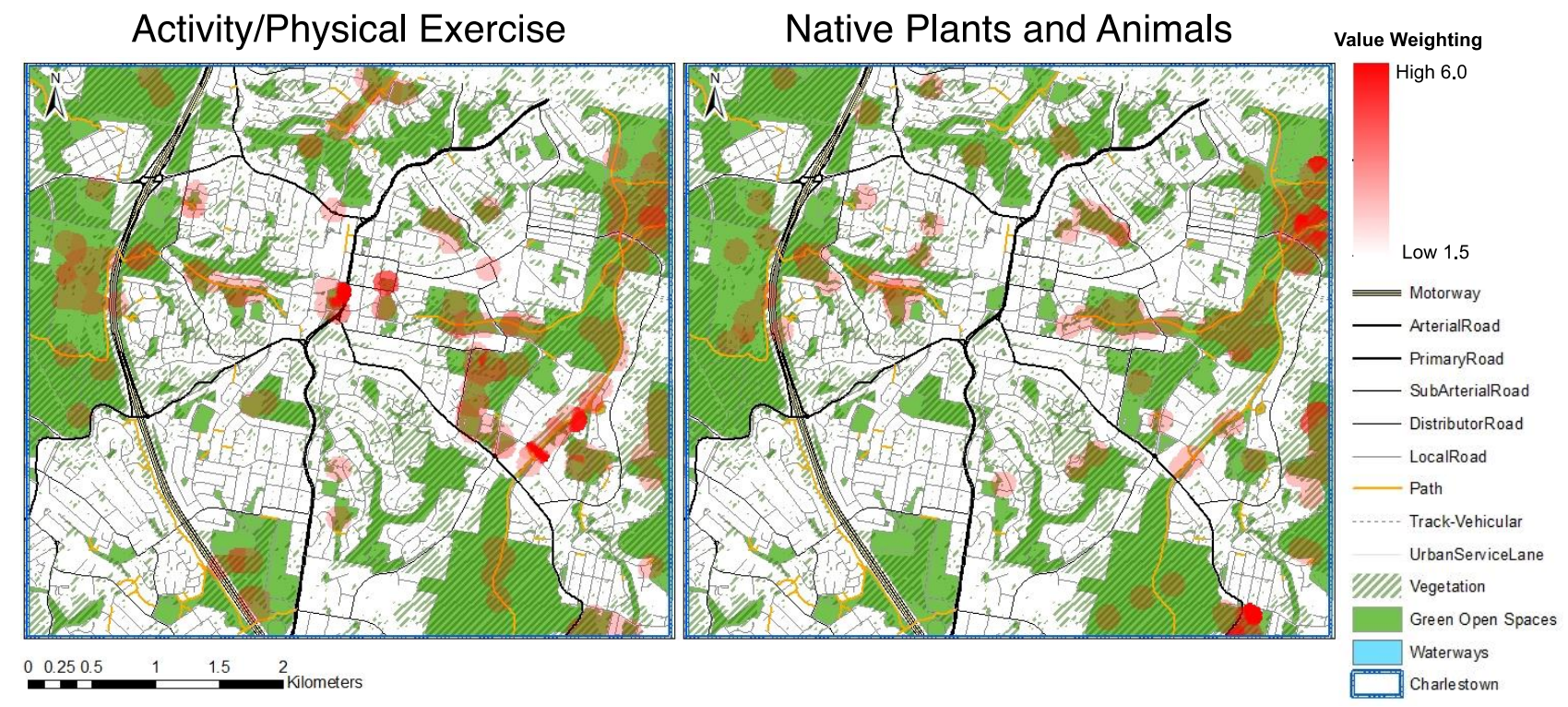

314 Figure 3. Inverse Distance Weighted maps of the spatial locations of mapped points, aggregated

315 for all respondents within Charlestown. The two panels demonstrate the differences between the

316 two value attributes. The numerical 'value weighting' score is proportional to the density of

317 marker dots at a location.

3.2 Environmental predictors of green space values.

320 Multivariate modelling revealed that different mapped values were related to different green

321 space characteristics. The final suite of variables retained in the best models according to AICc

322 indices is shown in Figure 4 (for full model statistics, see supplementary material S3). Distance

323 from water was the most regularly selected variable, having an important negative effect on the

324 abundance of marker dots in a green space (higher abundances in green spaces closer to water).

325 Many variables were found to have a non-linear effect on mapped values, as indicated by the

326 significant quadratic terms. Suburb was found to have a significant influence on half of the

327 measured value types, with green spaces in Charlestown found to have more mapped value dots

328 than the others in these cases. Regarding native plants and animals and nature values, the width

329 of a green space was positively related to the abundance of mapped dots. 


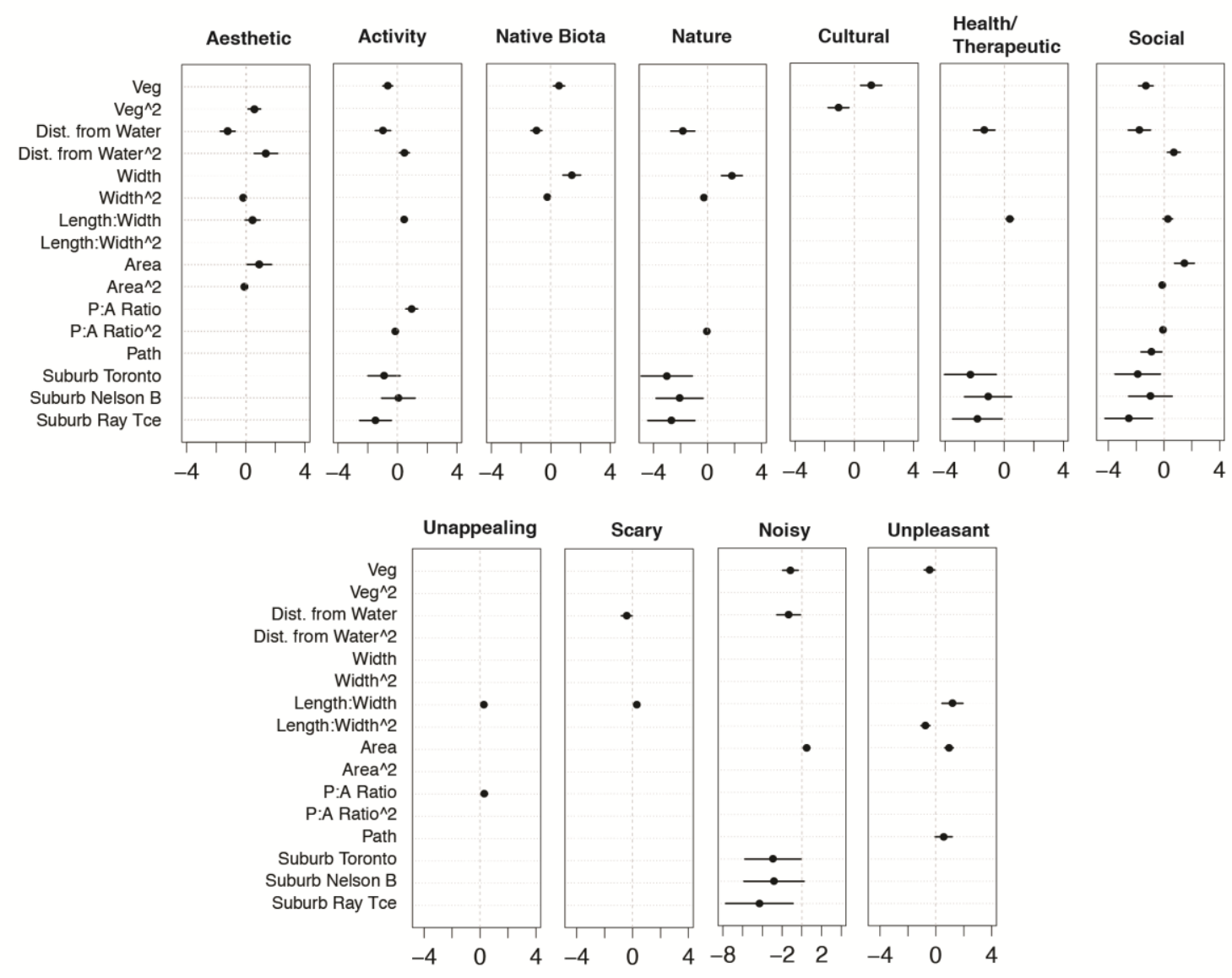

Effect Size of Variables Included in Best Model (Hurdle Negative Binomial Modelling)

331 Figure 4. Models of the green space values (the response variable), with the effect sizes of 332 different predictor variables (shown in each row). For variables retained in the final model, the 333 mean effect size is indicated by a black dot, along with its $95 \%$ credible interval as indicated by 334 the line. Quadratic terms are denoted by^ ${ }^{\wedge}$.

3.3 Effect of green space type (management classification)

337 Despite its significance for green space management, municipal planning classification was not

338 strongly related to the abundance of mapped marker dots for most values. Fig. 5 shows the

339 expected mean abundance of all values according to planning category. This analysis used the

340 same hurdle model as for other green space variables but included planning classification as the

341 only covariate (for full model statistics, see supplementary material S4). Of particular interest is

342 that green spaces designated as 'natural' areas did not have significantly more 'native plants and 
343 animals' or 'nature' values assigned to them than areas designated for 'general' use, when

344 considering the mean number of value markers at individual green space level

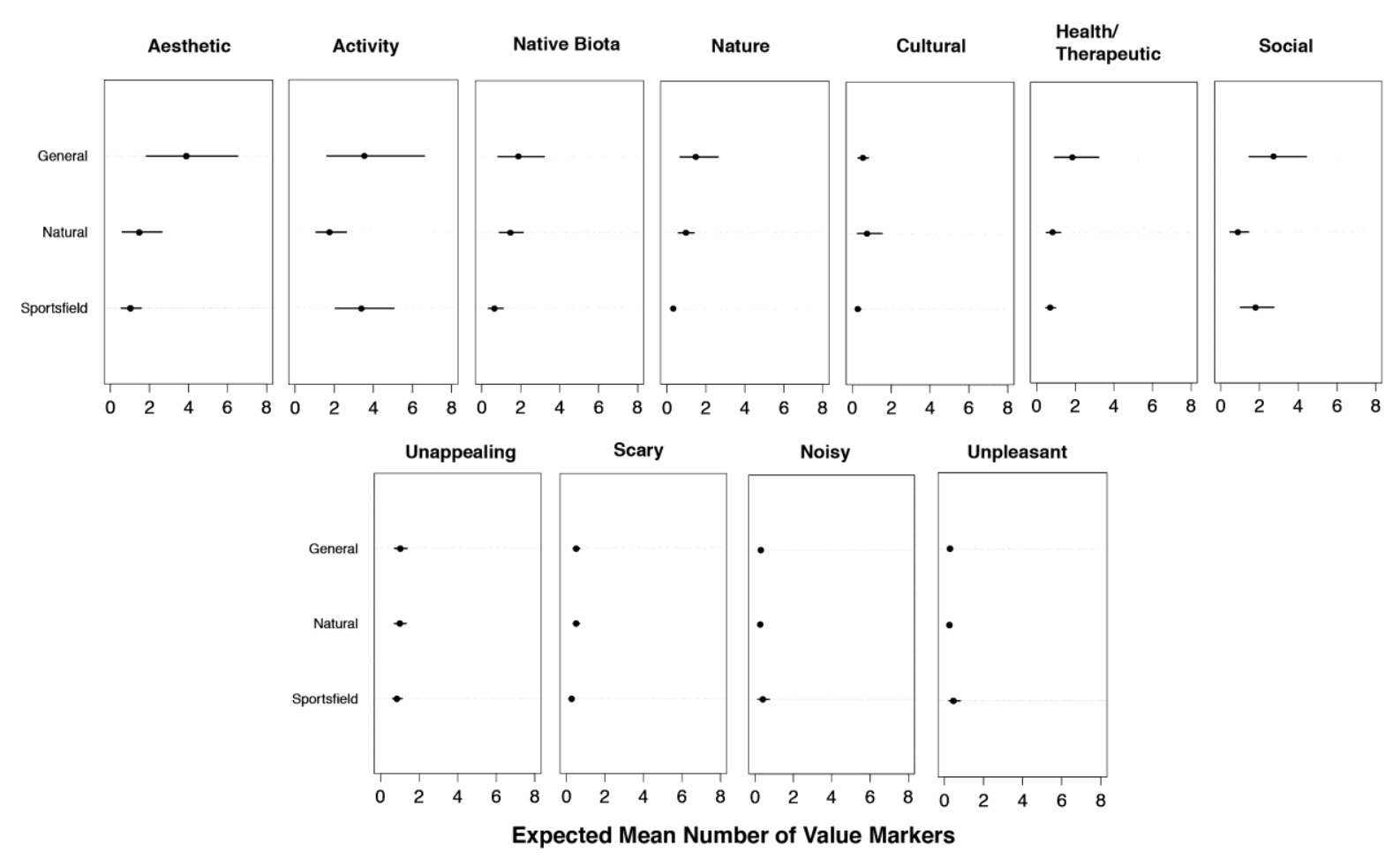

Figure 5. Expected mean abundance of value marker dots per green space polygon according to

347 green space management category. The black dots indicate the mean value and the lines indicate 348 the $95 \%$ credible interval.

\subsection{Distance from home}

351 Histograms of the proportion of marker dots assigned at different intervals from respondents'

352 place of residence showed peaks at between $1 \mathrm{~km}$ and $2 \mathrm{~km}$ for all suburbs (see Fig. 6, solid grey

353 bars). However, similar patterns were also observed for the randomised, null models (Fig. 6,

354 dashed bars). Chi-squared tests comparing the histogram bars of the two distributions revealed

355 that the two distributions were significantly different (Charlestown $\chi^{2}=398.98$, d.f. $=24, P=$

$356<0.001$; Nelson Bay $\chi^{2}=2243.80$, d.f. $=29, P=<0.001$; Raymond Terrace $\chi^{2}=700.41$, d.f. $=23$,

$357 P=<0.001$; Toronto $\chi^{2}=1017.6$, d.f. $\left.=22, P=<0.001\right)$. Plots of the differences between 
358 histogram bars for real and null distributions showed a disproportional abundance of value

359 markers nearer to place of residence for all values (particularly for distances $<2 \mathrm{~km}$ ), but this

360 pattern was relatively weak and more pronounced in some suburbs more than others (e.g.

361 Toronto) (see Fig. 6). Although some value attributes showed the strongest densities within $1 \mathrm{~km}$

362 of respondents' place of residence (e.g. social interaction value), others (especially negative

363 qualities) displayed no relationship with distance from home (see supplementary material S5). 


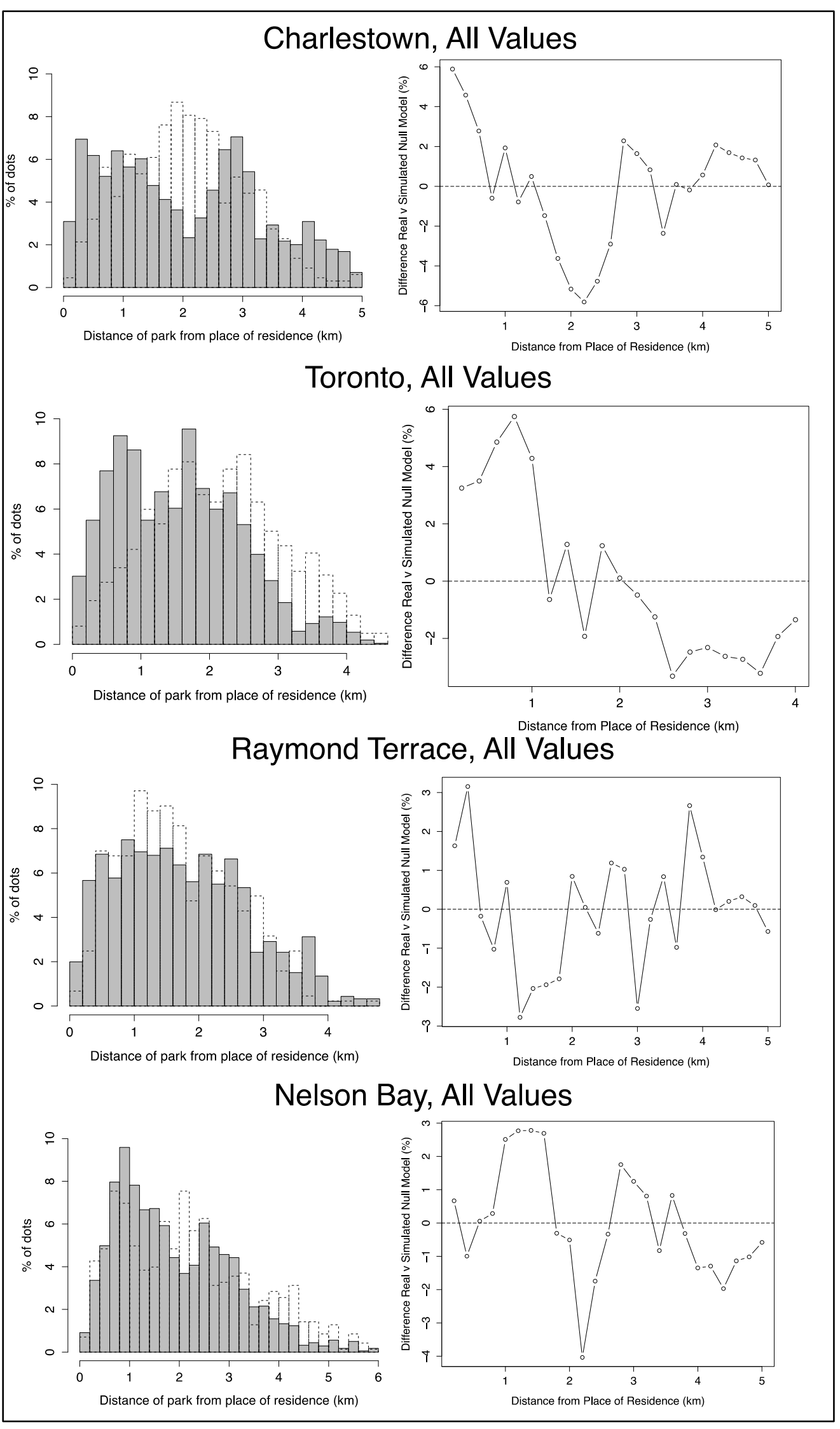


365 Figure 6. Plots of the association between assigned values (all marker dots) and distance from

366 place of residence. Histograms on the left-hand side show the proportion of marker dots at

367 different distances from respondents' place of residence. Differences between real and null

368 models (see methods) can be seen by comparing the solid grey bars (real data) with the dashed

369 bars (null models). Plots on the right-hand side show the difference between real and null-models

370 for the proportion of marker dots.

\subsection{Values compatibility.}

373 Some pairs of values were found to be more compatible (tended to co-occur in green spaces)

374 more than others. Some of the highest compatibility scores from the Spearman rank correlation

375 analysis were between Aesthetic \& Health/Therapeutic Value (Spearman's $\rho=0.714 ; P<$

376 0.001), Native Plants/Animals \& Nature Value $(\rho=0.745 ; P<0.001)$, Activity/Physical

377 Exercise \& Social Interaction Value $(\rho=0.674 ; P<0.001)$, Activity/Physical Exercise \&

378 Health/Therapeutic Value $(\rho=0.681 ; P<0.001)$, and Native Plants/Animals \&

379 Health/Therapeutic Value $(\rho=0.572 ; P<0.001)$. Factor analysis of mapped values identified

380 three factors with eigenvalues $>1$ (see Table 2). These correlations are confirmed, with the first

381 factor receiving highest loadings of nature and culture values, the second health and activity

382 values, and the third negative values. Interestingly, the fact that some green spaces are

383 considered noisy does not seem to compromise their activity, social interaction or health values

384 (see factor 2). In contrast, the other negative qualities all loaded on a single factor, suggesting

385 that these rarely are found alongside other values in green spaces. 
388 Table 2. Exploratory factor analysis of mapped values, with loadings $>0.4$ reported. Although 389 there is some overlap of values between factors, the factors help identify values that tend to co390 occur in green spaces.

\begin{tabular}{llll}
\hline & Factor 1 & Factor 2 & Factor 3 \\
\hline Aesthetic & 0.618 & 0.697 & \\
Activity & 0.416 & 0.774 & \\
Native plants and animals & 0.928 & & \\
Nature & 0.938 & & \\
Cultural significance & 0.662 & & \\
Health & 0.629 & 0.722 & \\
Social interaction & & 0.895 & 0.760 \\
Unappealing & & & 0.777 \\
Scary or unsafe & & 0.424 & 0.441 \\
Noisy & & & 1.813 \\
Unpleasant & 3.286 & 2.858 & 0.165 \\
Loadings & 0.299 & 0.260 & 0.723 \\
Proportion variance & 0.299 & 0.558 & \\
Cumulative variance & & &
\end{tabular}

\section{4. Discussion}

393 In this study we sought to understand how people in a rapidly urbanising region assign value to 394 green spaces and assess the influence of environmental variables on these values. These insights 395 are important for building the evidence base from PPGIS research methods that are increasing in 396 popularity. In particular, our study can provide guidance on how statistical methods can be 397 appropriately applied to PPGIS data. Further, given some continuing resistance to the use of 398 PPGIS methods by planning practitioners (Brown, 2015) a key research question of this study 399 was to explore useful insights into how PPGIS assessment of green spaces can be applied in 400 practice. These issues are discussed in turn below. 
403 The values people assigned to green space were very positive overall, with comparatively few 404 marker dots assigned that denoted negative qualities. This was true regardless of the type of 405 management applied to the green spaces (Fig. 5). Although ambivalent attitudes towards urban

406 green space have been observed (e.g. Bonnes, Passafaro, \& Carrus, 2010), our result is consistent 407 with the bulk of research that has shown green environments are generally perceived positively 408 (Kellert \& Wilson, 1995). For example, Kyttä et al. (2013) in their study of urban landscape 409 values in Finland found that $80 \%$ of value markers placed in green spaces denoted positive 410 attitudes.

412 The specific values assigned to green spaces were varied and responsive to a multiple

413 environmental variables. This suggests that people interact with landscapes in complex ways and 414 assign a plurality of values to them for different purposes, a result that has been found in other 415 landscapes (Ives \& Kendal, 2013; see Purcell, Lamb, Mainardi Peron, \& Falchero, 1994). We 416 encourage planners to consider the heterogeneity of green space values and stress that green 417 space networks for urban populations will require a 'portfolio of places' (Swanwick, 2009).

419 For many value attributes, green spaces closer to water bodies were valued more strongly than 420 those further away (see Fig. 4). This finding is consistent with most of the literature on public 421 preferences for landscapes (Swanwick, 2009), with people's affinity for water explained by the 422 theory that it enhances the perceived orderliness and naturalness of a scene (Kaplan \& Kaplan, 423 1989), as well as adding to the coherence of a landscape (Litton, Tetlow, \& Sorensen, 1974). 424 However, there is evidence that preferences for waterscapes can differ according to type and 425 context (Herzog, 1985). For example, a study in Victoria, Australia recently found that the public 
426 distinguished between six categories of wetlands according to the amount of water visible,

427 presence of trees, water quality and habitat value (Dobbie \& Green, 2012). Further, the literature

428 on 'ecological aesthetics' suggests that public preferences to landscapes is the result of a

429 combination of landscape features and individual factors like knowledge, values and attitudes

430 (Gobster, Nassauer, Daniel, \& Fry, 2007). Given the high compatibility observed between

431 aesthetic values and other values (Table 2), it is likely that the visual preferences for green

432 spaces near water lead to the assignment of other values in these places. There is therefore

433 potential to include additional analysis of water body type and individual psychological factors

434 in future PPGIS studies.

436 The proportion of vegetation present in a green space was related to the abundance of marker

437 dots for many value types (Fig. 4), yet the nature of its influence varied. For native plants and

438 animals, the relationship was a positive one, for social interaction values a negative relationship

439 was observed, while a quadratic relationship was found for aesthetic values (Fig. 4). The factors

440 behind the effect of vegetation on mapped values are likely to be highly complex, but some

441 existing theories and recent empirical studies can provide insight. We suggest that the

442 relationship between vegetation cover and mapped values may reflect landscape preference,

443 environmental perception, mental restoration, and the suitability of spaces for certain activities.

444 Recent research elsewhere from Brisbane, Australia, found that visitation of green spaces peaked

445 at intermediate levels of vegetation cover (Shanahan, Lin, Gaston, Bush, \& Fuller, 2015); a

446 pattern they attributed to theories that landscape preference is highest in savannah-type

447 landscapes (i.e. the information processing theory: Kaplan \& Kaplan, 1989). The positive effect

448 of vegetation on mental restoration has also been shown in a number of studies. For example, 
449 Nordh et al. (2009) showed greater likelihood of restoration in green spaces with increased cover 450 of trees and bushes, and Peschardt and Stigsdotter (2013) found that the 'natural' components of

451 urban green spaces (e.g. unstructured vegetation) were particularly important for increasing

452 perceived restorativeness in stressed individuals. The positive relationship between assigned

453 values for native plants and animals and vegetation cover is as would be expected, since people's

454 perception of biodiversity has been shown to relate strongly to vegetation cover (Dallimer et al.,

455 2012), even though this does not always align with scientific measurements of biodiversity such

456 as species richness. While there are many plausible theories that explain the results we have

457 observed, there is a need for greater exploration in future research of the specific mechanisms 458 that give rise to the observed mapped values.

460 Local governments in Australia regularly categorise green spaces according to their intended 461 purpose or use. Our study showed that in our case study areas, these categories had little to no 462 bearing on the abundance of value markers found in specific green spaces (Fig. 5). In particular, 463 we observed no statistical difference in the average abundance of marker dots for nature values 464 or native plants and animals values between green spaces designated as 'natural areas' and those 465 for 'general use' (Fig. 5). Our results suggest that formal categories may not have a strong 466 influence on the perceptions of local residents. This may either be because residents simply do 467 not strongly distinguish between these classes when valuing green spaces, or because residents 468 have little knowledge of the official designated purposes of the green spaces. Determining which 469 of these is the more accurate explanation is an area for future research. In terms of biodiversity 470 conservation, our findings present an opportunity for management agencies to maximise 
471 biodiversity across the whole landscape rather than focussing exclusively on formal nature

472 protection areas since residents value nature on all different kinds of green spaces.

474 Distance from place of residence did not have a clear relationship to the assignment of values to 475 green spaces, after accounting for landscape configuration (Fig. 6). Although distance from

476 home has been found to be an important factor influencing green space visitation (Neuvonen,

477 Sievänen, Tönnes, \& Koskela, 2007; Shanahan et al., 2015), it appears that landscape values, at

478 least in our case study, are quite different constructs and are less strongly influenced by spatial

479 proximity. The established theory of geographic or spatial discounting of values (Norton \&

480 Hannon, 1997) supposes that PPGIS respondents will place disproportionately more markers

481 closer to their home than more distal locations, as has been empirically shown by Brown et al.

482 (2002). Although this pattern can be seen in the suburb of Toronto, it was not evident for the

483 other suburbs. Thus, our analysis highlights the importance of accounting for the spatial bias in

484 the locations of landscape features (for example via simulation) in order to further explore the 485 spatial discounting hypothesis in relation to PPGIS.

487 Finally, we found that the compatibility between different value types (based on their co488 occurrence in green space polygons) varied substantially between value types. The highest 489 compatibility observed was between 'native plants \& animals' and 'nature' values, suggesting 490 that sampled residents do not distinguish substantially between these two concepts in the 491 Australian context. Further, high compatibility was also observed between 'native plants \& 492 animals' and 'health/therapeutic' values. Interestingly, in their study of public perceptions of 493 urban biodiversity, Voigt and Wurster (2015) found that 'diversity' was used to express a sense 
494 of well-being rather than an assessment of biological diversity or importance. This suggests that

495 there is a need for further research into what people are actually mapping when indicating

496 'nature' or 'biodiversity' values in PPGIS studies, but may also help to explain the compatibility

497 between nature and health values. Nevertheless, our results suggest that there is real potential for 498 green space planners and managers to improve both biodiversity conservation and public health 499 outcomes simultaneously (Lachowycz \& Jones, 2012; Lee \& Maheswaran, 2011).

\section{$501 \quad 4.2$ PPGIS in practice}

502 In considering how the insights from this study should be applied to planning practice, it is 503 useful to recognise the different scales at which research and planning practice can be reconciled 504 as proposed by Lindholst et al. (2015). First we consider applying insights at the policy level (i.e. 505 deriving general principles for planning green space), and second at the applied level (by 506 providing guidance for practitioners considering using PPGIS in a local context).

\subsubsection{Green space planning principles}

509 According to the landscape character variables retained in our models of green space values (Fig.

510 4), our results suggest that when designing new green space networks, priority should be placed

511 locating green spaces near water bodies where possible and ensuring green spaces are

512 sufficiently large for meaningful social interaction. Managers of existing green spaces should

513 seek to promote multiple values simultaneously in individual green spaces regardless of their

514 management category (Fig. 5). Based on the value compatibility assessment (Table 2), some

515 values may be promoted alongside one another more easily than others (e.g. health and social

516 interaction, or nature conservation, aesthetics and culture). Practitioners should therefore 
517 carefully plant and maintain vegetation in ways that are visually appealing and help to promote

518 biodiversity (Ives \& Kelly, 2016). Of course, applying these general principles is only one

519 element of good planning practice; practitioners should also seek to engage the community and

520 encourage participation in the decision-making process, as difficult as this process can be

521 (Chiesura, 2004). Indeed, the effect of 'suburb' on some of our models of open space values

522 (namely activity value, nature value, health/therapeutic value, social interaction value, and noisy;

523 see Fig. 4) suggests that the valuation of green spaces may be influenced by unique demographic

524 and environmental characteristics of specific areas. It is imperative therefore that planners

525 supplement any general principles with knowledge of the needs specific to a region.

\section{4.2.2. Guidance for practitioners applying PPGIS}

528 Many methods exist for public communication, consultation and participation, each with

529 strengths and weaknesses depending on the decision-making context (Reed, 2008). We consider

530 PPGIS to be a useful complement to existing methods for engaging communities in urban green

531 space planning. PPGIS is more participatory than approaches that emphasise information

532 dissemination such as town hall meetings or leaflets, more representative than charettes or

533 community planning forums, more spatially nuanced than public surveys, and more quantitative

534 than focus groups. Yet the mass collection of quantitative data can also mask certain issues and

535 subtle complexities that emerge through more deliberative, qualitative methods. PPGIS is

536 therefore likely to be a useful tool that builds upon existing understandings of the social-

537 ecological landscape and feeds back into the planning process in order for a just and sustainable 538 outcome to be reached. 
540 Our study identified a number of potential challenges and pitfalls that need to be considered by

541 urban landscape managers and planners seeking to apply PPGIS methods in a specific context. In

542 their study of participatory green space planning processes in Finland, Kahila-Tani et al. (2016)

543 noted that "though planners found the collected data and the analysis valuable, they still lacked

544 the skills and institutional motivation to use the data effectively" (p. 195). Below we provide

545 guidance along these lines that could assist urban planners in implementing PPGIS methods.

547 4.2.2.1 Evaluation of PPGIS design and analysis choices

548 If PPGIS data are used to inform decision-making, it is critical that they are accurate and reliable.

549 This study has identified a number of issues that need to be considered. First, it is important that

550 the sample frame is an accurate representation of the broader population's spatial, temporal and

551 socio-demographic variability. We strove to ensure a representative sample of participants, yet

552 even with appropriate survey design and administration measures taken we found some

553 demographic bias in our data. This has potential to overemphasise the importance of certain

554 values and places since different demographic groups interact with landscapes in different ways

555 (e.g. parents valuing safe areas for children to play). Any such bias should be recognised when

556 applying results to planning practice. Second, the spatial arrangement of respondents and

557 landscape features can impact results and their interpretation. By accounting for the relative

558 spatial distribution of green spaces to the respondents in our study areas, we found that the

559 distance of a green space from participants' place of residence did not have a strong effect on

560 marker abundance (Fig. 6). Failure to account for the relative locations of green spaces and

561 respondents could in many cases lead to inaccurate conclusions about how distance impacts

562 values, yet this kind of analysis is not a simple exercise for many management agencies. Finally, 
563 PPGIS studies are normally conducted at a single point in time. They typically do not capture

564 how people's values for landscapes change temporally in response to seasonality, change in life

565 circumstances, or landscape modification. Although a recent study found an overall consistency

566 in the values for an Alaskan national forest indicated via PPGIS mapping over a 14 year time

567 period (Brown \& Donovan, 2014), this is a topic that has received little attention in the literature

568 and is in need of further research, particularly in regards to individual responses and the

569 psychological antecedents of value assignment.

571 Another challenge in undertaking effective PPGIS research for green space planning is the 572 resources (time, money, expertise) it requires. Using physical paper maps is known to generate 573 higher response rates than online PPGIS methods (Pocewicz, Nielsen-Pincus, Brown, \&

574 Schnitzer, 2012), yet printing and postal costs can be prohibitive for many small municipalities.

575 The substantial time taken to digitise markers and analyse responses may also be problematic if

576 it exceeds the personnel time allocated by management agencies for community engagement. A

577 related challenge is ensuring agencies have the appropriate expertise (particularly statistical)

578 required to appropriately analyse and interpret results. We encourage the continuing

579 development of new methods to engage citizens using new technologies (e.g. smartphone apps)

580 and assist practitioners in data analysis as a way of helping to meet these challenges.

581 Additionally, if limited analytical skills are available, it may be more appropriate to simply use

582 visualisations of mapped values to identify immediate management priorities or issues rather

583 than seeking to extrapolate results to more generalised principles. 
586 Planning for green space is a complex process that brings together various social, environmental

587 and political considerations. Although the specifics of the planning process varies across

588 different places and times, Maruani and Amit-Cohen (2007) identified five general open space

589 planning models that have been applied in an urban context. In brief, these are (i) opportunistic

590 (random allocation of land for open space according to availability), (ii) space standards

591 (providing minimum area of open space for a given population), (iii) park systems (interrelated

592 parks and gardens), (iv) garden city (a comprehensive approach based on Ebenezer Howard's

593 principles), and (v) shape related models (such as green belts or green wedges). We suggest that

594 PPGIS can help transition urban green space planning from traditional standards-based or shape-

595 based planning models to a participatory, 'needs-based' planning approach: one that accounts for

596 a population's “socio-demographic composition, their leisure and recreation preferences and

597 those of various sub-groups" (Byrne \& Sipe, 2010). Yet there is still some work needed to

598 mainstream new deliberative-analytic processes in green space planning (Kahila-Tani et al.,

599 2016). Combining PPGIS with other participatory tools for stakeholder engagement is likely to

600 help overcome some of the methodological challenges discussed above and aid the inclusion of

601 citizens' epistemological and ontological diversity (Kahila-Tani et al., 2016; Nahuelhual, Benra

602 Ochoa, Rojas, Díaz, \& Carmona, 2016).

603

604 5. Conclusion

605 This study has demonstrated that public values for green space are varied and respond in 606 different ways to different suites of environmental variables. While some environmental 607 variables seemed to exert a consistently positive effect on all environmental variables (e.g. 608 distance from water), other variables (e.g. vegetation cover) were related only to a few value 
609 types. Further, existing management categories were shown not to have a strong bearing on the

610 kinds of values people assign to green spaces. This research reveals a complex picture of how

611 different values are assigned to green spaces, and highlights the need for green space planners to

612 avoid the 'one size fits all' approach to the design of green space networks. We encourage

613 planners to pursue participatory techniques such as PPGIS as a means of ascertaining the values

614 and preferences of the urban public and planning for these accordingly. Yet we also emphasise

615 the need for careful consideration of the design and analysis of these methods to ensure that the

616 data used to inform decisions are accurate and reliable.

\section{Acknowledgements}

619 This work was conducted with funding support from the Australian Government's National

620 Environmental Research Program, Environmental Decisions Hub. The authors thank Port

621 Stephens City Council and Lake Macquarie City Council for their advice and support for the

622 project, and the residents who participated in the survey. Christopher Raymond is thanked for his

623 assistance with the study design. Benjamin Cooke also assisted greatly with the administration of

624 the survey.

625

626 References

627 Australian Bureau of Statistics. (2011). QuickStats: A simple at-a-glance summary of Census

628 statistics for your local area. Retrieved September 19, 2016, from

629 http://www.abs.gov.au/websitedbs/censushome.nsf/home/quickstats

630 Balram, S., \& Dragićević, S. (2005). Attitudes toward urban green spaces: integrating 631 questionnaire survey and collaborative GIS techniques to improve attitude measurements. $632 \quad$ Landscape and Urban Planning, 71(2-4), 147-162. 
Ives et al. (2017) Landscape and Urban Planning 161: 32-43

633

634

635

636

637

638

639

640

641

642

643

644

645

646

647

648

649

650

651

652

653

654

655

656

657

658

659

660

https://doi.org/10.1016/j.landurbplan.2004.02.007

Beckmw. (2013). Collinearity and stepwise VIF selection. Retrieved March 1, 2015, from https://beckmw.wordpress.com/2013/02/05/collinearity-and-stepwise-vif-selection/

Bonnes, M., Passafaro, P., \& Carrus, G. (2010). The Ambivalence of Attitudes Toward Urban Green Areas: Between Proenvironmental Worldviews and Daily Residential Experience. Environment and Behavior, 43(2), 207-232. https://doi.org/10.1177/0013916509354699

Brown, G. (2008). A theory of urban park geography. Journal of Leisure Research, 40(4), 589607. Retrieved from http://www.landscapemap2.org/publications/JLR_Brown.pdf

Brown, G. (2012). Public Participation GIS (PPGIS) for regional and Environmental Planning: reflections on a decade of Empirical research. URISA Journal, 25(2), 7-18. Retrieved from http://www.landscapemap2.org/publications/urisa_journal_2012.pdf

Brown, G. (2015). Engaging the wisdom of crowds and public judgement for land use planning using public participation geographic information systems. Australian Planner, 52(3), 199209. https://doi.org/10.1080/07293682.2015.1034147

Brown, G., \& Donovan, S. (2014). Measuring Change in Place Values for Environmental and Natural Resource Planning Using Public Participation GIS (PPGIS): Results and Challenges for Longitudinal Research. Society \& Natural Resources, 27(1), 36-54. https://doi.org/10.1080/08941920.2013.840023

Brown, G. G., Reed, P., \& Harris, C. C. (2002). Testing a place-based theory for environmental evaluation: An Alaska case study. Applied Geography, 22(1), 49-76. JOUR. https://doi.org/10.1016/S0143-6228(01)00019-4

Brown, G., Schebella, M. F., \& Weber, D. (2014). Using participatory GIS to measure physical activity and urban park benefits. Landscape and Urban Planning, 121, 34-44. https://doi.org/10.1016/j.landurbplan.2013.09.006

Brown, T. (1984). The Concept of Value in Resource Allocation. Land Economics, 60(3), 231246. Retrieved from http://www.jstor.org/stable/10.2307/3146184

Byrne, J., \& Sipe, N. (2010). Green and open space planning for urban consolidation - A review of the literature and best practice. 
661 Campbell, H. (2012). Planning to Change the World: Between Knowledge and Action Lies

662 Synthesis. Journal of Planning Education and Research, 32(2), 135-146.

663 https://doi.org/10.1177/0739456X11436347

664

Chiesura, A. (2004). The role of urban parks for the sustainable city. Landscape and Urban Planning, 68, 129-138. https://doi.org/10.1016/j.landurbplan.2003.08.003

Dallimer, M., Irvine, K. N., Skinner, A. M. J., Davies, Z. G., Rouquette, J. R., Maltby, L. L., ... Gaston, K. J. (2012). Biodiversity and the Feel-Good Factor: Understanding Associations between Self-Reported Human Well-being and Species Richness. BioScience, 62(1), 47-55.

Dobbie, M., \& Green, R. (2012). Public perceptions of freshwater wetlands in Victoria, Australia. Landscape and Urban Planning, 110, 143-154. https://doi.org/10.1016/j.landurbplan.2012.11.003

Gobster, P. H., Nassauer, J. I., Daniel, T. C., \& Fry, G. (2007). The shared landscape: what does

Grahn, P., Stigsdotter, U., \& Berggren-Bärring, A. M. (2005). Human issues: eight experienced qualities in urban open spaces. In Final report of COST action (pp. 240-247).

Herzog, T. R. (1985). A cognitive analysis of preference for waterscapes. Journal of Space. Landscape and Urban Planning, 118, 98-102. https://doi.org/10.1016/j.landurbplan.2012.09.006 urban greenspace: a semi-systematic review. Urban Ecosystems, 18(4), 1139-1163. https://doi.org/10.1007/s11252-015-0456-6 
689

690

691

692

693

694

695

696

697

698

699

700

Ives, C. D., \& Kelly, A. H. (2016). The coexistence of amenity and biodiversity in urban landscapes. Landscape Research. https://doi.org/10.1080/01426397.2015.1081161

Ives, C. D., \& Kendal, D. (2013). Values and attitudes of the urban public towards peri-urban agricultural land. Land Use Policy, 34, 80-90. Retrieved from http://www.sciencedirect.com/science/article/pii/S026483771300032X

Ives, C. D., \& Kendal, D. (2014). The role of social values in the management of ecological systems. Journal of Environmental Management, 144, 67-72. https://doi.org/10.1016/j.jenvman.2014.05.013

Jackman, S. (2015). pscl: Classes and Methods for R Developed in the Political Science Computational Laboratory, Stanford University. Retrieved from http://pscl.stanford.edu/

Jorgensen, A., \& Gobster, P. H. (2010). Shades of Green: Measuring the Ecology of Urban Green Space in the Context of Human Health and Well-Being. Nature and Culture, 5(3), 338-363. https://doi.org/10.3167/nc.2010.050307

Kabisch, N., Qureshi, S., \& Haase, D. (2015). Human - environment interactions in urban green spaces - A systematic review of contemporary issues and prospects for future research, 50, $25-34$.

Kahila-Tani, M., Broberg, A., Kyttä, M., \& Tyger, T. (2016). Let the Citizens Map-Public Participation GIS as a Planning Support System in the Helsinki Master Plan Process. Planning Practice \& Research, 31(2), 195-214. https://doi.org/10.1080/02697459.2015.1104203

Kaplan, R., \& Kaplan, S. (1989). Experience of Nature: A Psychological Perspective. New York: Cambridge University Press.

Kellert, S. R., \& Wilson, E. O. (1995). The Biophilia Hypothesis. Washington, D.C: Island Press. Kenter, J. O., O’Brien, L., Hockley, N., Ravenscroft, N., Fazey, I., Irvine, K. N., ... Williams, S. (2015). What are shared and social values of ecosystems? Ecological Economics, 111, 8699. https://doi.org/10.1016/j.ecolecon.2015.01.006

Konijnendijk, C. C., Annerstedt, M., Nielsen, A. B., \& Maruthaveeran, S. (2013). Benefits of Urban Parks: A systematic review. 
Kyttä, M., Broberg, A., Tzoulas, T., \& Snabb, K. (2013). Towards contextually sensitive urban densification: Location-based softGIS knowledge revealing perceived residential environmental quality. Landscape and Urban Planning, 113, 30-46. https://doi.org/10.1016/j.landurbplan.2013.01.008

Lachowycz, K., \& Jones, A. P. (2012). Towards a better understanding of the relationship between greenspace and health: Development of a theoretical framework. Landscape and Urban Planning, 8-15. https://doi.org/10.1016/j.landurbplan.2012.10.012

Lee, A. C. K., \& Maheswaran, R. (2011). The health benefits of urban green spaces: a review of the evidence. Journal of Public Health (Oxford, England), 33(2), 212-22. https://doi.org/10.1093/pubmed/fdq068

Lindholst, A. C., Caspersen, O. H., \& Konijnendijk Van Den Bosch, C. C. (2015). Methods for mapping recreational and social values in urban green spaces in the nordic countries and their comparative merits for urban planning. Journal of Outdoor Recreation and Tourism, 12, 71-81. https://doi.org/10.1016/j.jort.2015.11.007

Litton, R. B., Tetlow, R. J., \& Sorensen, J. (1974). Water and Landscape: An Aesthetic Overview of the Role of Water in the Landscape. New York: Water Information Center.

Luederitz, C., Brink, E., Gralla, F., Hermelingmeier, V., Meyer, M., Niven, L., ... von Wehrden, H. (2015). A review of urban ecosystem services: Six key challenges for future research. Ecosystem Services, 14, 98-112. JOUR. https://doi.org/10.1016/j.ecoser.2015.05.001

Maruani, T., \& Amit-Cohen, I. (2007). Open space planning models: A review of approaches and methods. Landscape and Urban Planning, 81, 1-13. https://doi.org/10.1016/j.landurbplan.2007.01.003

McCormack, G. R., Rock, M., Toohey, A. M., \& Hignell, D. (2010). Characteristics of urban parks associated with park use and physical activity: A review of qualitative research. Health and Place, 16(4), 712-726. https://doi.org/10.1016/j.healthplace.2010.03.003

Nahuelhual, L., Benra Ochoa, F., Rojas, F., Díaz, G. I., \& Carmona, A. (2016). Mapping social values of ecosystem services: What is behind the map? Ecology and Society, 21(3), art24. https://doi.org/10.5751/ES-08676-210324 
Neuvonen, M., Sievänen, T., Tönnes, S., \& Koskela, T. (2007). Access to green areas and the frequency of visits - A case study in Helsinki. Urban Forestry and Urban Greening, 6(4), 235-247. https://doi.org/10.1016/j.ufug.2007.05.003

Nordh, H., Hartig, T., Hagerhall, C. M., \& Fry, G. (2009). Components of small urban parks that predict the possibility for restoration. Urban Forestry and Urban Greening, 8(4), 225-235. https://doi.org/10.1016/j.ufug.2009.06.003

Norton, B., \& Hannon, B. (1997). Environmental values: a place-based theory. Environmental Ethics, 19(3), 227-245. Retrieved from http://scholar.google.com/scholar?hl=en\&btnG=Search\&q=intitle:Environmental+values:+a +place-based+theory\#0

Peschardt, K., \& Stigsdotter, U. (2013). Associations between park characteristics and perceived restorativeness of small public urban green spaces. Landscape and Urban Planning, 112, 26-39. Retrieved from http://www.sciencedirect.com/science/article/pii/S0169204612003519

Plieninger, T., Bieling, C., Fagerholm, N., Byg, A., Hartel, T., Hurley, P., ... Huntsinger, L. (2015). The role of cultural ecosystem services in landscape management and planning. Current Opinion in Environmental Sustainability, 14, 28-33. https://doi.org/10.1016/j.cosust.2015.02.006

Plieninger, T., Dijks, S., Oteros-Rozas, E., \& Bieling, C. (2013). Assessing, mapping, and quantifying cultural ecosystem services at community level. Land Use Policy, 33, 118-129. JOUR. https://doi.org/10.1016/j.landusepol.2012.12.013

Pocewicz, A., Nielsen-Pincus, M., Brown, G., \& Schnitzer, R. (2012). An Evaluation of Internet Versus Paper-based Methods for Public Participation Geographic Information Systems (PPGIS). Transactions in Gis, 16(1), 39-53. Journal Article. https://doi.org/10.1111/j.14679671.2011.01287.x

Purcell, A. T., Lamb, R. J., Mainardi Peron, E., \& Falchero, S. (1994). Preference or preferences for landscape? Journal of Environmental Psychology, 14, 195-209. https://doi.org/10.1146/annurev.psych.47.1.485 
773 R Development Core Team. (2016). R: A language and environment for statistical computing. R Foundation for Statistical Computing.

775

776

777

778

779

780

781

782

783

784

785

786

787

788

789

790

792

793

794

795

796

797

798

799

800

Raymond, C. M., \& Curtis, A. (2013). Mapping community values for regional sustainability in the Lower Hunter region of NSW. NERP Landscape and Policy Research Hub, The University of Tasmania.

Reed, M. S. (2008). Stakeholder participation for environmental management: A literature review. Biological Conservation, 141(10), 2417-2431. https://doi.org/10.1016/j.biocon.2008.07.014

Shanahan, D. F., Lin, B. B., Gaston, K. J., Bush, R., \& Fuller, R. a. (2015). What is the role of trees and remnant vegetation in attracting people to urban parks? Landscape Ecology, 30(1), 153-165. https://doi.org/10.1007/s10980-014-0113-0

Swanwick, C. (2009). Society's attitudes to and preferences for land and landscape. Land Use Policy, 26, S62-S75. https://doi.org/10.1016/j.landusepol.2009.08.025

Swanwick, C., Dunnett, N., \& Woolley, H. (2003). Nature, Role and Value of Green Space in Towns and Cities: An Overview. Built Environment, 29(2), 94-106. https://doi.org/10.2148/benv.29.2.94.54467

Tratalos, J. A., Haines-Young, R., Potschin, M., Fish, R., \& Church, A. (2015). Cultural ecosystem services in the UK: Lessons on designing indicators to inform management and policy. Ecological Indicators. https://doi.org/10.1016/j.ecolind.2015.03.040

Tulloch, D. (2008). Public Participation GIS ( PPGIS ). In K. K. Kemp (Ed.), Encyclopedia of Geographic Information Science (pp. 352-354). Thousand Oaks: SAGE Publications.

Tyrväinen, L., Mäkinen, K., \& Schipperijn, J. (2007). Tools for mapping social values of urban woodlands and other green areas. Landscape and Urban Planning, 79(1), 5-19. https://doi.org/10.1016/j.landurbplan.2006.03.003

Van Herzele, A., \& van Woerkum, C. (2011). On the argumentative work of map-based visualisation. Landscape and Urban Planning, 100(4), 396-399. https://doi.org/10.1016/j.landurbplan.2011.02.013

Voigt, A., \& Wurster, D. (2015). Does diversity matter? The experience of urban nature's 
801 diversity: Case study and cultural concept. Ecosystem Services, 12, 200-208. JOUR.

802 https://doi.org/10.1016/j.ecoser.2014.12.005

803 Wates, N. (2014). The Community Planning Handbook: How people can shape their cities,

$804 \quad$ towns \& villages in any part of the world. New York: Routledge.

805 Zeileis, A., Kleiber, C., \& Jackman, S. (2008). Regression Models for Count Data in R. Journal 806 of Statistical Software, 27, 1-25.

807 Zube, E. H. (1987). Perceived land use patterns and landscape values. Landscape Ecology, I(I), $808 \quad 37-45$.

809 